Bond University

Research Repository

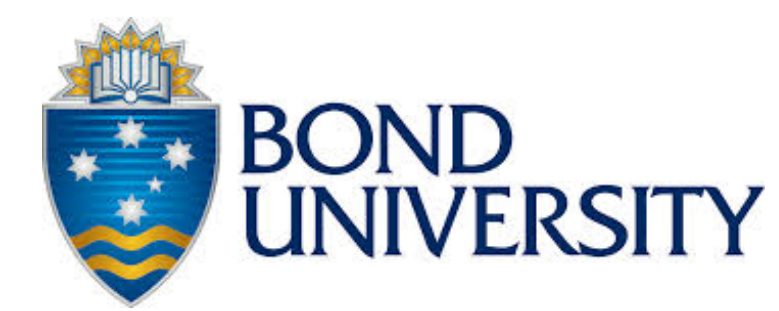

\title{
Concentrations of plasma-borne extracellular particles differ between multiple sclerosis disease courses and compared to healthy controls
}

Groen, Kira; Maltby, Vicki E.; Scott, Rodney J.; Tajouri, Lotti; Lechner-Scott, Jeannette

Published in:

Multiple Sclerosis and Related Disorders

DOI:

10.1016/j.msard.2020.102446

Licence:

CC BY-NC-ND

Link to output in Bond University research repository.

Recommended citation(APA):

Groen, K., Maltby, V. E., Scott, R. J., Tajouri, L., \& Lechner-Scott, J. (2020). Concentrations of plasma-borne extracellular particles differ between multiple sclerosis disease courses and compared to healthy controls. Multiple Sclerosis and Related Disorders, 45, [102446]. https://doi.org/10.1016/j.msard.2020.102446

\section{General rights}

Copyright and moral rights for the publications made accessible in the public portal are retained by the authors and/or other copyright owners and it is a condition of accessing publications that users recognise and abide by the legal requirements associated with these rights.

For more information, or if you believe that this document breaches copyright, please contact the Bond University research repository coordinator. 


\section{Concentrations of plasma-borne extracellular particles differ}

\section{between Multiple Sclerosis disease courses and compared to}

\section{healthy controls.}

Kira Groen $^{1,2}$, Vicki E. Maltby ${ }^{1,2,3}$, Rodney J. Scott ${ }^{4,5,6}$, Lotti Tajouri ${ }^{7,8}$, Jeannette Lechner$\operatorname{Scott}^{1,2,3}$

1. School of Medicine and Public Health, University of Newcastle, Callaghan NSW 2308, Australia

2. Centre for Brain and Mental Health Research, Hunter Medical Research Institute, New Lambton Heights NSW 2305, Australia

3. Department of Neurology, John Hunter Hospital, New Lambton Heights NSW 2305, Australia

4. Cancer, Hunter Medical Research Institute, New Lambton Heights NSW 2305, Australia

5. Division of Molecular Medicine, Pathology North, John Hunter Hospital, New Lambton Heights NSW 2305, Australia

6. School of Biomedical Sciences and Pharmacy, University of Newcastle, Callaghan NSW 2308, Australia

7. Faculty of Health Sciences and Medicine, Bond University, Robina QLD 4229, Australia

8. Dubai Police Scientific Council and Dubai Future Council on Community Security, Dubai, United Arab Emirates

\section{Emails:}

kira.groen@newcastle.au, vicki.e.maltby@newcastle.edu.au, rodney.scott@newcastle.edu.au, ltajouri@bond.edu.au, jeannette.lechner-scott@health.nsw.gov.au

\section{Corresponding Author:}

Kira Groen

Level 3 West, Hunter Medical Research Institute

Lot 1 Kookaburra Circuit

New Lambton Heights NSW 2305

Australia

Email: kira.groen@newcastle.edu.au

Telephone: +61 49213540 


\section{Abstract:}

Background: Multiple Sclerosis is a neurodegenerative, autoimmune disease of the central nervous system. Both peripheral blood and central nervous system facets play a role in the pathophysiology. Extracellular vesicles are small membrane-bound vesicles that are released by most cells in response to stress, activation, or pathology. As extracellular vesicles can cross the blood-brain barrier, they have the ability to link peripheral blood inflammation to central nervous system pathology in Multiple Sclerosis. The aim of this study was to obtain a comprehensive picture of the cellular origins of plasma-borne extracellular particles in Multiple Sclerosis.

Methods: Platelet-free plasma was obtained from 39 Multiple Sclerosis patients and 27 healthy controls via a series of centrifugation steps and assessed by flow cytometry. Plasma samples were stained with antibodies against CD4, CD8, CD14, CD20, CD41b, CD45, CD146, and CD235a. Gates were set using size-reference beads and extracellular particles were enumerated using commercial counting beads at known concentrations.

Results: In relapsing patients ( $\mathrm{n}=13)$ erythrocyte-derived (CD235a) extracellular particles were increased, while platelet-derived (CD41b), leukocyte-derived (CD45), and CD4 ${ }^{+} \mathrm{T}$ cellderived (CD4) extracellular particles were decreased compared to both healthy controls $(n=27)$ $(\mathrm{p}<0.01)$ and secondary progressive Multiple Sclerosis patients $(\mathrm{n}=9)(\mathrm{p}<0.05)$. Endotheliumderived extracellular particles were increased in stable relapsing-remitting Multiple Sclerosis patients $(n=17)$ compared to healthy controls $(\mathrm{p}<0.05)$. Extracellular particles from several different cells of origin correlated with each other and clinical parameters (e.g. disease duration, number of relapses, EDSS), though clinical correlations did not withstand corrections for multiple comparisons. 
Conclusions: Concentrations of erythrocyte-, leukocyte-, and platelet-derived extracellular particles were altered in relapsing Multiple Sclerosis patients and endothelium-derived extracellular particles were increased in stable relapsing-remitting patients compared to healthy controls. Extracellular particles may provide insights into altered crosstalk between peripheral blood cells in Multiple Sclerosis, which may lead to the discovery of novel therapeutic targets.

\section{Keywords:}

Extracellular vesicles, Multiple Sclerosis, platelets, endothelium, $\mathrm{CD}^{+} \mathrm{T}$ cells, erythrocytes 

Abbreviations:
adj.p adjusted p-value
AF auto-fluorescence
BBB blood-brain barrier
CD cluster of differentiation
CNS central nervous system
CSF cerebrospinal fluid
DMT disease-modifying therapy
EDSS expanded disability status scale
EP extracellular particle
EV extracellular vesicle
HC healthy control
IQR interquartile range
MISEV2018 minimal information for the studies of extracellular vesicles 2018
MRI magnetic resonance imaging
MS Multiple Sclerosis
n/a not applicable/not available/no answer
PPMS primary progressive Multiple Sclerosis
RRMS relapsing-remitting Multiple Sclerosis
SD standard deviation of the mean
SNP single nucleotide polymorphism
SPMS secondary progressive Multiple Sclerosis 


\section{Introduction:}

Extracellular vesicles (EVs) are small membrane-bound vesicles. EVs are receiving increasing attention due to their involvement in intercellular communication (Abels and Breakefield, 2016). Formerly considered cell debris, EVs are now known to be taken up by recipient cells and the cargo delivered to such recipient cells can be functional (Ridder et al., 2014). EVs are released in response to activation, stress, or pathology and their classification is based on biogenesis and size. Microvesicles, formed through outward budding of the plasma membrane, range from $100 \mathrm{~nm}$ to $1 \mu \mathrm{m}$. Exosomes are released upon fusion of multivesicular bodies with the plasma membrane and range from $30 \mathrm{~nm}$ to $150 \mathrm{~nm}$ (Abels and Breakefield, 2016). Distinguishing between EV subspecies is challenging, which has led to some confusion in the field. To circumvent this issue, both microvesicles and exosomes will be referred to as EVs. EVs can carry membrane proteins from their cell of origin on the outer membrane. Such proteins can be surveyed to determine the cellular origin of EVs in biological fluids (Zaborowski et al., 2015).

EVs can be detected in biological fluids such as blood (Enjeti et al., 2016), urine (Pisitkun et al., 2004), cerebrospinal fluid (CSF) (An et al., 2013), and saliva (Iwai et al., 2017). In these fluids, EVs have provided an intriguing new source of potential biomarkers for many diseases, including Multiple Sclerosis (MS) (Saenz-Cuesta et al., 2014a). MS is a chronic inflammatory, autoimmune disease with a neurodegenerative component. Both the peripheral compartment and the central nervous system (CNS) are involved in MS (Dendrou et al., 2015). From a phenotypical standpoint, MS can be characterised as relapsing-remitting MS (RRMS), secondary progressive MS (SPMS), and primary progressive MS (PPMS) (Lublin et al., 2014). There are currently no blood-borne biomarkers specific to MS. Circulating EVs represent an attractive source of MS-specific biomarkers as they have the ability to cross the blood-brain barrier (BBB) (Matsumoto et al., 2017a; Matsumoto et al., 2017b); thus, they may link 
peripheral inflammation to CNS pathology. Additionally, EVs from the CNS may transverse the BBB and access the peripheral circulation, where they have been detected (García-Romero et al., 2017) and from where they may contribute to systemic inflammation (Dickens et al., 2017).

In MS, several circulating EVs have been assessed using flow cytometry. During relapse, an increase in plasma endothelial EVs $\left(\mathrm{CD} 31^{+}\right.$and $\left.\mathrm{CD} 51^{+}\right)$has been observed (Marcos-Ramiro et al., 2014; Minagar et al., 2001). The increase in endothelial-derived EVs was also detected in other clinical forms of MS including RRMS, SPMS, and clinically isolated syndrome (MarcosRamiro et al., 2014). Some endothelial EVs $\left(\mathrm{CD} 51^{+}\right)$remained elevated in remission, possibly indicating chronic BBB damage (Minagar et al., 2001). Endothelial EVs were found to form complexes with leukocytes and these complexes correlated positively with gadoliniumenhancing lesions identified using magnetic resonance imaging (MRI). Endothelial EVs appeared to preferentially bind and activate monocytes over lymphocytes and neutrophils in vitro (Jy et al., 2004). Activated monocytes were found to facilitate transendothelial migration, a crucial step in MS pathology (Jy et al., 2004).

Similar to endothelium-derived EVs, platelet-derived EVs were found to be increased in MS patients compared to healthy controls (HCs) (Marcos-Ramiro et al., 2014; Saenz-Cuesta et al., 2014a), while B cell-derived EVs (CD19+) were decreased (Zinger et al., 2016). Collectively, circulating EVs from MS patients were found to cause greater disruption of endothelial barriers than circulating EVs from $\mathrm{HCs}$ at equal concentrations, highlighting their potential involvement in MS pathology (Marcos-Ramiro et al., 2014). Differences in circulating EVs were also observed between MS phenotypes, with greatest increases in platelet-, leukocyte-, and monocyte-derived EVs observed in RRMS, while SPMS patients had levels resembling those of HCs (Saenz-Cuesta et al., 2014a). These observations support the hypothesis that MS is more confined to the CNS in progressive disease (Dendrou et al., 2015). Disease-modifying 
therapies (DMTs) have been found to alter the levels of circulating EVs. Interferon $1 \beta$ (Sheremata et al., 2006) and fingolimod (Zinger et al., 2016) brought about a decrease in circulating endothelium-derived EVs.

A comprehensive study of plasma-borne EVs may provide insights into the involvement of peripheral blood cells in MS pathology and indicate sources of novel biomarkers. The aim of this study was to undertake a comprehensive survey of circulating extracellular particles (EPs) in MS patients and HCs, and to identify potential links to disease activity and disability. 


\section{Methods:}

\subsection{Ethics statement:}

Ethical approval for this study was obtained from the University of Newcastle (H-505-0607) and the Hunter New England Health Ethics Committee (2019/ETH12346). Participants were recruited through the MS clinic at the John Hunter Hospital and the Hunter Medical Research Institute. All participants gave written informed consent.

\subsection{Cohort:}

Inclusion criteria were: MS patients had to 1) be $\geq 18$ years old, 2) meet $2017 \mathrm{McD}$ onald criteria for MS (Thompson et al., 2018), 3) be treatment-naïve or off DMT for > 6 months prior to sample collection (exceptions were made for relapse samples) and 4) not have received corticosteroids in the 90 days prior to sample collection (exceptions were made for relapse samples). Patients were excluded if they had an autoimmune condition other than MS. HCs were age- ( \pm two years) and gender-matched and could not suffer from any autoimmune or CNS disease. Exclusion criteria were participants who were pregnant or breastfeeding. Additional patient information was obtained through MSBase (Butzkueven et al., 2006) and HCs completed a questionnaire. Physical activity levels of patients and HCs were self-reported and based on the Exercise and Sport Science Australia Intensity Guidelines (Norton et al., 2010). Patients were considered stable, "RRMS" from here on, if they had not presented with any new clinical symptoms or gadolinium-enhancing lesions on MRI in the 120 days precollection and 90 days post-collection. Active relapse, "Relapse" from here on, was defined as new MS-related symptoms or evidence of gadolinium-enhancing lesions on MRI within a month of sample collection. Information regarding infectious diseases was not recorded at the time of sample collection. 
The cohort consisted of 17 RRMS patients, 13 Relapse patients, 9 SPMS patients, and 27 HCs. Six of the relapsing patients $(46.2 \%)$ received corticosteroids in the three months prior to sample collection. All participants were female and all collected blood samples were nonfasting blood samples.

\subsection{Blood processing:}

Nine $\mathrm{mL}$ of blood were collected into lithium-heparin coated vacutainers (Vacuette, Greiner Bio-One, Austria). All blood samples were processed within six hours of collection and $83 \%$ of samples were processed within four hours of collection. Platelet-free plasma was obtained via centrifugation $(1500 \mathrm{x} \mathrm{g}$ for $15 \mathrm{~min}$ at room temperature with break off, $2500 \mathrm{x} \mathrm{g}$ for 10 min at room temperature with break on, $4500 \mathrm{x}$ g for $15 \mathrm{~min}$ at $4{ }^{\circ} \mathrm{C}$ with break on). Plateletfree plasma was stored at $-80^{\circ} \mathrm{C}$ until samples were stained for flow cytometry. Haemolysis was checked visually using a colour scale when samples were thawed. This enrichment method falls into the category of "high recovery, low specificity" according to the Minimal Information for Studies of Extracellular Vesicles 2018 (MISEV2018) guidelines (Thery et al., 2018). Due to the enrichment method's lack of specificity, plasma-borne particles of this study are termed extracellular particles (EPs), not EVs.

\subsection{SDS-PAGE and western blotting:}

Platelet-free plasma samples were diluted 1:20 with phosphate-buffered saline, mixed with sample loading buffer (Tris-HCl, glycerol, 2\% SDS, bromophenol blue, $\beta$-mercaptoethanol) and boiled at $95^{\circ} \mathrm{C}$ for five minutes prior to being size separated by elcetrophoresis on a $10 \%$ polyacrylamide gel $(150 \mathrm{~V}, 60-70 \mathrm{~min})$. Size separated proteins were transferred to a nitrocellulose membrane (100 V, $60 \mathrm{~min})$, which was blocked with Odyssey blocking buffer

(LICOR Biosciences, USA), and incubated with primary antibodies overnight. The following primary antibodies were used: mouse anti-ApoA1 (1:1000), mouse anti-CD63 (1:1000), mouse 
anti-Alix (1:1000), and rabbit anti-albumin (1:750). All primary antibodies were purchased from Thermo Fisher Scientific (USA). Secondary IRDye-conjugated antibodies (goat antirabbit and donkey-anti-mouse, 1:25,000) were purchased from LICOR Biosciences (USA) and added to the membranes for one hour. Membranes were scanned on a LICOR Odyssey scanner (LICOR Biosciences, USA).

\subsection{Total protein assay:}

Total protein concentrations were determined with the Qubit protein assay kit (Invitrogen, USA) as per manufacturer instructions. Plasma samples were diluted 1:39 with Milli Q water for the protein assay.

\subsection{Flow cytometry:}

Ten $\mu$ l platelet-free plasma was stained with fluorescently labelled antibodies against CD235a (APC, Clone GA-R2), CD41b (FITC, Clone HIP2), CD45 (FITC, Clone 2D1), CD146 (PE, Clone P1H12), CD20 (APC, Clone 2H), CD4 (FITC, Clone OKT4), CD8a (FITC, Clone RPAT8), and CD14 (APC, Clone RPA-T8). Antibodies were purchased from BD Pharmingen, USA (CD235a, CD41b, CD20, CD14), Invitrogen, USA (CD146), and StemCell, Canada (CD45, CD4, CD8). Table 1 shows cells typically expressing the used CD markers. 
Table 1: Expression of selected CD markers on circulating blood cells and the endothelium.

\begin{tabular}{|c|c|c|c|c|c|c|c|c|c|c|c|}
\hline CD & Name & $\bar{\Xi}$ & 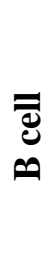 & 总 & $\begin{array}{l}\bar{\Xi} \\
\text { z }\end{array}$ & 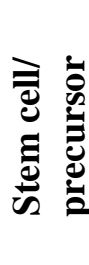 & 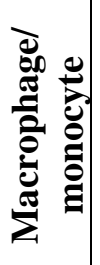 & 莺 & $\frac{\frac{\vec{\omega}}{\pi}}{\frac{\pi}{2}}$ & 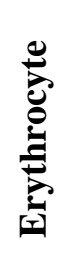 & 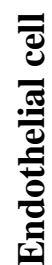 \\
\hline CD4 & L3T4, W3/25, T4, Leu3a & + & - & & - & - & + & + & - & - & - \\
\hline CD8a & Leu2, T8, Lyt2,3 & + & - & & + & - & - & - & - & - & - \\
\hline CD14 & LPS-receptor & - & - & & - & & + & + & & & \\
\hline CD20 & $\mathrm{B} 1, \mathrm{Bp} 35$ & + & + & - & - & - & - & - & - & - & - \\
\hline CD41b & $\begin{array}{l}\text { GPIIb, integrin } \alpha \mathrm{IIb}, \\
\text { platelet membrane } \\
\text { glycoprotein IIb, } \\
\text { ITGA2B, integrin } \alpha 2 b, \\
\text { human platelet antigen } 3\end{array}$ & - & - & - & - & + & - & - & + & - & - \\
\hline CD45 & $\begin{array}{c}\text { Leukocyte common } \\
\text { antigen, T200, B220, Ly5, } \\
\text { PTRPC }\end{array}$ & + & + & + & + & + & + & + & - & - & - \\
\hline CD146 & $\begin{array}{c}\text { Muc-18, S-endo, MCAM, } \\
\text { Mel-CAM }\end{array}$ & + & - & & - & & - & - & - & - & + \\
\hline CD235a & $\begin{array}{c}\text { Glycophorin A, } \\
\text { sialoglycoprotein } \alpha, \\
\text { sialoglycoprotein A, MN } \\
\text { blood group antigen, } \\
\text { PAS-2 }\end{array}$ & - & - & - & - & + & - & - & & + & \\
\hline
\end{tabular}

Highlighted cells indicate for which cell(s) the CD markers were used for in this study. This table was adapted from bdbiosciences.com/cdmarkers. CD - cluster of differentiation.

Samples were run on a modified LSRFortessa (BD Biosciences, USA) with a $0.1 \mu \mathrm{m}$ sheath fluid filter. Staining buffer was filtered with $0.1 \mu \mathrm{m}$ filters. Size gates were set using flow cytometer calibration and size reference beads (Invitrogen, USA). An EP gate was set for events that were $<1 \mu \mathrm{m}$. With synthetic size reference beads observing different light scattering than biological EPs, size gates are only an approximation of the EPs' size. Plasma EPs were quantified using CountBright beads (Invitrogen, USA). Negative controls (staining buffer and antibodies only, no sample) were run with every batch of samples. Samples were highly diluted (dilution factor $=40$ ) and run at low flow rate to mitigate coincidence. Plasma EP concentrations were calculated as follows: 


$$
\begin{gathered}
\text { plasma EPs }(\text { per } \mu l)=\left(\left(\left(\frac{\# E P s}{\# \text { beads }} * b\right) * \text { dilution factor }\right)-a\right) *(1-A F) \\
\text { b(bead concentration in sample })=\frac{\text { bead concentration } * \text { bead volume }}{\text { total volume }} \\
a(\text { EPs in negative control })=\left(\frac{\# E P s}{\# \text { beads }} * b\right) * \text { dilution factor } \\
A F-\text { autofluorescence }
\end{gathered}
$$

With the BD LSR Fortessa with photomultiplier tube upgrade being able to differentiate particles of > $200 \mathrm{~nm}$ from background noise, EPs surveyed by flow cytometry were large EPs (Thery et al., 2018).

\subsection{Statistics:}

Statistical analysis was performed in R (v. 3.6.1). Distribution of the data was checked visually, (box plots and histograms), and through kurtosis and skewness measures. The data followed a non-parametric distribution. Therefore, EP data is reported as median and interquartile range (IQR). Differences between groups were determined using Wilcoxon signed-rank test. Significance threshold was set at $\mathrm{p}<0.05$. Correlations between EPs were determined through Pearson's correlation coefficients and correlations between EPs and clinical parameters were determined through Spearman's rho. P-values were adjusted for multiple comparisons using the Benjamini-Hochberg approach. 


\section{Results:}

Participant demographics are summarised in Table 2. Of the relapsing patients, four patients were on DMT at the time of sample collection $(1 \mathrm{x}$ fingolimod, $1 \mathrm{x}$ glatiramer acetate, $2 \mathrm{x}$ interferon). Additional participant and sample information is summarised in Supplementary File $S 1$.

Table 2: Participant demographics.

\begin{tabular}{|c|c|c|c|c|c|}
\hline & $\begin{array}{c}\text { HC } \\
(\text { RRMS)* }\end{array}$ & $\begin{array}{c}\text { HC } \\
\text { (SPMS)* }\end{array}$ & Relapse & RRMS & SPMS \\
\hline $\mathbf{n}$ & 17 & 10 & 13 & 17 & 9 \\
\hline Age (years) & $\begin{array}{c}50.6 \\
( \pm 11.9)\end{array}$ & $\begin{array}{c}60.0 \\
( \pm 6.5)\end{array}$ & $\begin{array}{c}38.0 \\
( \pm 12.0)\end{array}$ & $\begin{array}{c}51.0 \\
( \pm 12.2)\end{array}$ & $\begin{array}{c}59.4 \\
( \pm 9.7)\end{array}$ \\
\hline Bench time (hours) & $2.2( \pm 1.4)$ & $\begin{array}{c}1.8 \\
( \pm 1.3)\end{array}$ & $\begin{array}{c}3.4 \\
( \pm 1.2)\end{array}$ & $\begin{array}{c}2.9 \\
( \pm 1.3)\end{array}$ & $\begin{array}{c}2.4 \\
( \pm 1.1)\end{array}$ \\
\hline Disease duration (years) & $\mathrm{n} / \mathrm{a}$ & $\mathrm{n} / \mathrm{a}$ & $\begin{array}{c}6.0 \\
( \pm 6.5)\end{array}$ & $\begin{array}{c}14.7 \\
( \pm 10.7)\end{array}$ & $\begin{array}{c}26.9 \\
( \pm 14.2)\end{array}$ \\
\hline $\begin{array}{l}\text { Progression duration } \\
\text { (years) }\end{array}$ & & & $\mathrm{n} / \mathrm{a}$ & $\mathrm{n} / \mathrm{a}$ & $\begin{array}{c}13.0 \\
( \pm 17.4) \\
\end{array}$ \\
\hline EDSS score & & & $\begin{array}{c}3.0 \\
( \pm 1.8)\end{array}$ & $\begin{array}{c}1.6 \\
( \pm 1.0)\end{array}$ & $\begin{array}{c}5.7 \\
( \pm 2.2)\end{array}$ \\
\hline Age at onset (years) & & & $\begin{array}{c}30.2 \\
( \pm 10.7)\end{array}$ & $\begin{array}{c}34.8 \\
( \pm 10.4)\end{array}$ & $\begin{array}{c}29.1 \\
( \pm 15.5)\end{array}$ \\
\hline Number of relapses & & & $4( \pm 5)$ & $4( \pm 3)$ & $5( \pm 4)$ \\
\hline $\begin{array}{l}\text { Steroids in the last } 3 \\
\text { months (\% yes) }\end{array}$ & & & 46.2 & 0 & 0 \\
\hline Days since last relapse & & & $\begin{array}{c}18 \\
( \pm 15)\end{array}$ & $\begin{array}{c}1510 \\
( \pm 1614)\end{array}$ & $\begin{array}{c}5052 \\
( \pm 5759)\end{array}$ \\
\hline
\end{tabular}

*HC were split into HC (RRMS) and HC (SPMS) to highlight age-matching of the HCs to RRMS and SPMS patients. As no correlations were identified between EPs and age in the HC group (see 3.4 Suggestive correlations between circulating EPs and clinical parameters), we decided not to split the controls for subsequent analyses. Data is shown as mean ( \pm SD). EDSS - expanded disability status scale; HC - healthy control; RRMS - relapsing-remitting Multiple Sclerosis; SD - standard deviation of the mean; SPMS - secondary progressive Multiple Sclerosis; n/a - not applicable. 


\subsection{EP Characteristics:}

All samples showed minimal signs of haemolysis ( $<20 \mathrm{mg} / \mathrm{dL}$ haemoglobin). Samples contained evidence of EV markers CD63 (EV transmembrane protein) and Alix (EV cytosolic protein) (Thery et al., 2018), but also of contaminants typically found in plasma (albumin and lipoproteins, indicated through presence of ApoA1) (Fig. 1). Together with the low total particle:protein ratios (Supplementary Table S2), this indicates an enrichment protocol of "high recovery [and] low specificity" (Thery et al., 2018), thus surveyed particles have been termed EPs.

With the modified LSR Fortessa's size detection limit lying around $200 \mathrm{~nm}$, EPs surveyed as part of this study were large EPs (200-1000 nm). Flow cytometry gating strategies are shown in Figure 2. Around $10 \%$ of all extracellular particles stained for selected CD markers across all four groups (, Table 3, Supplementary Figure S2). Total EP numbers varied from 2,430,248 (IQR: 3,415,552) in relapse patients $(\mathrm{n}=13)$ to 3,440,895 (IQR: 41,543,052) in SPMS patients (Table 3). There were no correlations between EP numbers and bench time (Supplementary Table S3). 
Table 3: Percent (\%) extracellular particles stained for selected cluster of differentiation markers.

\begin{tabular}{|l|c|c|c|c|}
\hline & $\begin{array}{l}\text { HCs } \\
(\mathbf{n = 2 7})\end{array}$ & $\begin{array}{l}\text { Relapse } \\
(\mathbf{n = 1 3})\end{array}$ & $\begin{array}{l}\text { RRMS } \\
(\mathbf{n = 1 7})\end{array}$ & $\begin{array}{l}\text { SPMS } \\
(\mathbf{n = 9})\end{array}$ \\
\hline $\begin{array}{l}\text { Total EPs } \\
\text { Median (IQR) }\end{array}$ & $\begin{array}{c}3,111,240 \\
(2,386,420)\end{array}$ & $\begin{array}{c}2,430,248 \\
(3,415,552)\end{array}$ & $\begin{array}{c}2,772,496 \\
(3,592,271)\end{array}$ & $\begin{array}{c}3,440,895 \\
(41,543,052)\end{array}$ \\
\hline $\begin{array}{l}\text { CD235a EPs } \\
(\%)\end{array}$ & 1.29 & 5.19 & 3.20 & 1.96 \\
\hline $\begin{array}{l}\text { CD41b EPs } \\
(\%)\end{array}$ & 3.98 & 1.29 & 2.71 & 5.72 \\
\hline $\begin{array}{l}\text { CD146 EPs } \\
(\%)\end{array}$ & 0.85 & 2.34 & 1.45 & 1.12 \\
\hline $\begin{array}{l}\text { CD45 EPs } \\
(\%)\end{array}$ & 0.79 & 0.47 & 0.69 & 1.02 \\
\hline $\begin{array}{l}\text { CD4 EPs } \\
(\%)\end{array}$ & 1.53 & 0.09 & 1.87 & 0.70 \\
\hline $\begin{array}{l}\text { CD20 EP } \\
(\%) \text { s }\end{array}$ & 0.20 & 0.24 & 0.28 & 0.21 \\
\hline $\begin{array}{l}\text { CD8 EPs } \\
(\%)\end{array}$ & 0.27 & 0.21 & 0.22 & 0.09 \\
\hline $\begin{array}{l}\text { CD14 EPs } \\
(\%)\end{array}$ & 0.01 & 10.04 & 10.58 & 0.15 \\
\hline $\begin{array}{l}\text { All stained EPs } \\
(\%)\end{array}$ & 0.20 & 0.16 & 10.97 \\
\hline
\end{tabular}

EPs of 200-1000 nm diameter are reported. EP - extracellular particle; HC - healthy control; IQR - interquartile range; RRMS-relapsing-remitting Multiple Sclerosis; SPMS - secondary progressive Multiple Sclerosis. 


\subsection{Differences in circulating EP numbers between MS disease courses and HCs:}

The levels of circulating EPs of different cellular origins varied between MS patients and HCs, as well as between MS patients of different disease courses. In HCs, platelet-derived EPs were the most prevalent, followed by erythrocyte-, leukocyte-, and endothelium-derived EPs respectively. In relapse patients, erythrocyte-derived EPs were most prevalent, followed by endothelium-, platelet-, and leukocyte-derived EPs. In RRMS patients, erythrocyte-derived EPs were the most prevalent plasma EPs, followed by platelet-, endothelium-, and leukocytederived EPs. In SPMS patients, platelet-derived EPs were the most prevalent plasma EPs, followed by erythrocyte-, endothelium-, and leukocyte-derived EPs ( Fig. 4, Supplementary Table S4).

Erythrocyte-derived EPs (CD235a): Erythrocyte-derived EPs were more abundant in relapse patients compared to HCs $(\mathrm{p}<0.001)$ and SPMS patients $(\mathrm{p}<0.05)$. There was a trend towards increased erythrocyte-derived EPs in stable RRMS patients compared to HCs, though this was not statistically significant.

Platelet-derived EPs (CD41b): Platelet-derived EPs were decreased in relapse patients compared to HCs $(\mathrm{p}<0.01)$ and SPMS patients $(\mathrm{p}<0.05)$. No further differences in plateletderived EPs were observed.

Endothelium-derived EPs (CD146): Endothelium-derived EPs were increased in RRMS patients compared to HCs $(\mathrm{p}<0.05)$. No other differences in endothelium-derived EPs were observed.

Leukocyte-derived EPs (CD45): Leukocyte-derived EPs were decreased in relapse patients compared to HCs $(\mathrm{p}<0.05)$ and SPMS patients $(\mathrm{p}<0.05)$. No further differences in leukocytederived EPs were observed. Leukocyte-derived EPs can be further divided into immune cell 
subsets. To look at these subsets in more detail, $\mathrm{CD} 4^{+} \mathrm{T}$ cell-, $\mathrm{CD} 8^{+} \mathrm{T}$ cell-, $\mathrm{B}$ cell-, and monocyte-derived EP numbers were assessed.

$\mathrm{CD} 4^{+} \mathrm{T}$ cell-derived EPs: Relapse patients' $\mathrm{CD}^{+} \mathrm{T}$ cell-derived EPs were decreased compared to $\mathrm{HC} \mathrm{CD} 4^{+} \mathrm{T}$ cell-derived EPs ( $\left.\mathrm{p}<0.001\right)$, RRMS patient $\mathrm{CD}^{+}{ }^{+} \mathrm{T}$ cell-derived EPs $(\mathrm{p}<0.001)$, and SPMS patient CD4 ${ }^{+} \mathrm{T}$ cell-derived EPs $(\mathrm{p}<0.05)$.

There were no significant differences in EPs from any other immune cell subsets.

\subsection{EPs from different cells of origin correlated with each other:}

The numbers of several plasma-borne EPs showed moderate $(0.7>r>0.5)$ to strong $(r \geq 0.7)$ correlation with each other (Table 4).

In all samples combined (HCs and MS, n =66), leukocyte-derived EPs positively correlated with both $\mathrm{CD}^{+} \mathrm{T}$ cell-derived EPs $(\mathrm{r}=0.636$; adj.p $=1.74 \mathrm{E}-06)$ and platelet-derived EPs $(\mathrm{r}=$ 0.488; adj.p = 0.004); B cell-derived EPs positively correlated with monocyte-derived EPs ( $\mathrm{r}$ $=0.595 ;$ adj.p $=2.50 \mathrm{E}-05)$; and erythrocyte-derived EPs positively correlated with endothelial cell-derived EPs $(r=0.596$; adj.p = 1.79E-05).

In HC samples $(\mathrm{n}=27)$, platelet-derived EPs positively correlated with endothelium-derived EPs $(r=0.716$; adj.p $=0.003)$.

In SPMS patient samples $(n=9)$, leukocyte-derived EPs positively correlated with $\mathrm{CD}^{+} \mathrm{T}$ cell-derived EPs $(r=0.952 ;$ adj.p $=0.010)$.

The best correlations between EP subtypes were observed in relapse patients $(n=13)$, where $\mathrm{CD}^{+} \mathrm{T}$ cell-derived EPs positively correlated with $\mathrm{CD}^{+} \mathrm{T}$ cell-derived EPs $(\mathrm{r}=0.951$; adj.p $=8.25 \mathrm{E}-05)$, platelet-derived EPs $(\mathrm{r}=0.961 ;$ adj.p $=2.37 \mathrm{E}-05)$, and leukocyte-derived EPs $(\mathrm{r}$ $=0.956$; adj.p $=4.68 \mathrm{E}-05)$. Additionally, $\mathrm{CD}^{+} \mathrm{T}$ cell-derived EPs positively correlated with platelet-derived EPs $(r=0.966$; adj. $\mathrm{p}=1.23 \mathrm{E}-05)$ and leukocyte-derived EPs $(r=0.950$ adj.p 
$=8.62 \mathrm{E}-05)$. Leukocyte-derived EPs positively with platelet-derived EPs $(\mathrm{r}=0.986$ adj. $\mathrm{p}=$ 8.33E-05).

No correlations between circulating EPs were identified in RRMS patients. 
Table 4: Pearson's correlation coefficients between extracellular particle subtypes.

\begin{tabular}{|l|c|c|c|c|}
\hline EPs & $\begin{array}{c}\text { All samples } \\
(\mathbf{n}=\mathbf{6 6})\end{array}$ & $\begin{array}{c}\text { HC } \\
(\mathbf{n}=\mathbf{2 7})\end{array}$ & $\begin{array}{c}\text { Relapse } \\
(\mathbf{n}=\mathbf{1 3})\end{array}$ & $\begin{array}{c}\text { SPMS } \\
(\mathbf{n}=\mathbf{9})\end{array}$ \\
\hline CD4 \& CD8 & & & $\begin{array}{c}0.951 \\
(\mathrm{p}=8.25 \mathrm{E}-05)\end{array}$ & \\
\hline CD4 \& CD41b & & $\begin{array}{c}0.961 \\
(\mathrm{p}=2.37 \mathrm{E}-05)\end{array}$ & \\
\hline CD4 \& CD45 & & $\begin{array}{c}0.956 \\
(\mathrm{p}=4.68 \mathrm{E}-05)\end{array}$ & \\
\hline CD8 \& CD41b & & $\begin{array}{c}0.966 \\
(\mathrm{p}=1.23 \mathrm{E}-05)\end{array}$ & \\
\hline CD8 \& CD45 & $\begin{array}{c}0.6369 \\
(\mathrm{p}=1.74 \mathrm{E}-06)\end{array}$ & & $\begin{array}{c}0.950 \\
(\mathrm{p}=8.62 \mathrm{E}-05)\end{array}$ & $\begin{array}{c}0.952 \\
(\mathrm{p}=0.010)\end{array}$ \\
\hline CD14 \& CD20 & $\begin{array}{c}0.594 \\
(\mathrm{p}=2.50 \mathrm{E}-05)\end{array}$ & & $\begin{array}{c}0.986 \\
(\mathrm{p}=8.33 \mathrm{E}-05)\end{array}$ & \\
\hline CD41b \& CD45 & $\begin{array}{c}0.488 \\
(\mathrm{p}=0.004)\end{array}$ & & & \\
\hline CD41b \& CD146 & & 0.716 & & \\
\hline CD146 \& CD235a & $\begin{array}{c}0.596 \\
(\mathrm{p}=1.79 \mathrm{E}-05)\end{array}$ & & $0.003)$ & \\
\hline
\end{tabular}

p-values have been adjusted for multiple comparisons. EP - extracellular particle; $\mathrm{HC}$ - healthy control; SPMS - secondary progressive Multiple Sclerosis. 


\subsection{Suggestive correlations between circulating EPs and clinical parameters:}

Circulating EP levels also showed suggestive correlations with a range of clinical parameters. These correlations showed trends in the direction of increase/decrease that were statistically significant prior to multiple comparison corrections but did not withstand this statistical correction (Table 5). Adjusted p-values nearing significance are highlighted throughout the following paragraphs.

In all MS patients, $\mathrm{CD}^{+} \mathrm{T}$ cell-derived EPs decreased with longer disease duration and increased with later age of onset. Both platelet- (adjusted p-value $=0.136$ ) and leukocytederived EPs increased with time since last relapse; matching the trend of decreased plateletand leukocyte-derived EPs in relapsing patients compared to SPMS patients (Fig. 3).

In RRMS patients, $\mathrm{CD}^{+}{ }^{+} \mathrm{T}$ cell-derived EPs decreased as time since patients' last relapse increased. B cell-derived EPs increased with increasing disability measured by expanded disability status scale (EDSS) scores and endothelium-derived EPs increased with increasing relapses since onset of the disease.

In SPMS patients, both $\mathrm{CD}^{+} \mathrm{T}$ cell-derived EPs and endothelium-derived EPs decreased with increasing disease duration, while B cell-derived EPs increased with increasing progression duration (adjusted p-value $=0.055$ ). The more relapses SPMS patients had experienced throughout their disease, the lower their number of circulating monocyte-derived EPs; and the more physically active the patient, the lower their B cell-derived EPs. Platelet-derived EPs decreased with age in SPMS patients and leukocyte-derived EPs were more numerous in patients with older ages of onset (adjusted $\mathrm{p}$-value $=0.157$ ), while decreasing with increasing time since patients' last relapse.

In relapse patients, $\mathrm{CD} 8^{+} \mathrm{T}$ cell-derived EPs were found to positively correlate with patients' body mass index and platelet-derived EPs negatively correlated with patients' EDSS scores. 
Correlations between EP numbers and clinical parameters (age, body mass index, physical activity level, disease duration, age at onset, time since last relapse, number of relapses since disease onset, progression duration and EDSS score) were checked for all groups (HCs, Relapse, RRMS and SPMS) as applicable. All correlations that were statistically significant prior to corrections for multiple comparisons are shown in Table 5.

Table 5: Correlations (Spearman's rho) between plasma extracellular particles and clinical parameters.

\begin{tabular}{|c|c|c|c|}
\hline \multirow{2}{*}{ EP } & \multirow{2}{*}{ Clinical parameter } & \multicolumn{2}{|r|}{ MS } \\
\hline & & rho & p-value (p.adj) \\
\hline \multirow{2}{*}{ CD8 } & Disease duration & -0.345 & $0.003(0.222)$ \\
\hline & Age at onset & 0.472 & $0.003(0.222)$ \\
\hline CD41b & \multirow{2}{*}{ Time since last relapse } & 0.481 & $0.002(0.136)$ \\
\hline CD45 & & 0.37 & $0.02(0.994)$ \\
\hline & & \multicolumn{2}{|r|}{ Relapse } \\
\hline & & rho & p-value (p.adj) \\
\hline CD8 & Body mass index & 0.833 & $0.01(0.641)$ \\
\hline \multirow[t]{3}{*}{ CD41b } & EDSS score & -0.749 & $0.008(0.512)$ \\
\hline & & \multicolumn{2}{|r|}{ RRMS } \\
\hline & & rho & p-value (p.adj) \\
\hline CD4 & Time since last relapse & -0.627 & $0.007(0.442)$ \\
\hline CD20 & $\begin{array}{c}\text { EDSS score } \\
\end{array}$ & 0.514 & $0.041(0.924)$ \\
\hline \multirow[t]{3}{*}{ CD146 } & $\begin{array}{c}\text { Number of relapses since } \\
\text { onset }\end{array}$ & 0.561 & $0.019(0.925)$ \\
\hline & & \multicolumn{2}{|r|}{ SPMS } \\
\hline & & rho & p-value (p.adj) \\
\hline CD8 & Disease duration & -0.717 & $0.03(0.983)$ \\
\hline CD14 & $\begin{array}{c}\text { Number of relapses since } \\
\text { onset }\end{array}$ & -0.681 & $0.044(0.983)$ \\
\hline \multirow[t]{2}{*}{ CD20 } & Progression duration & 0.929 & $0.001(0.055)$ \\
\hline & Physical activity & -0.729 & $0.040(0.983)$ \\
\hline CD41b & Age & -0.733 & $0.025(0.982)$ \\
\hline \multirow[t]{2}{*}{ CD45 } & Time since last relapse & -0.677 & $0.05(0.983)$ \\
\hline & Age at onset & 0.867 & $0.002(0.157)$ \\
\hline CD146 & Disease duration & -0.667 & $0.05(0.983)$ \\
\hline
\end{tabular}

EDSS - expanded disability status scale; EP - extracellular particle; MS - Multiple Sclerosis; p.adj - adjusted p-value; RRMS - relapsing-remitting Multiple Sclerosis; SPMS - secondary progressive Multiple Sclerosis. 


\section{Discussion:}

Altered levels of immune cell-derived EPs (CD45 and CD4) were detected, but differences in erythrocyte-derived (CD235a), endothelium-derived (CD146), and platelet-derived (CD41b) EPs were also evident. Many of the EP subtypes correlated both with each other and suggestively correlated with clinical measures in MS. While the enrichment protocol did not exclusively isolate EVs, differences in EPs highlighted by this study may still provide insights into potential EV sources and disease biomarkers.

MS is assumed to be an autoimmune disease that relies on both dysfunctional T and B cells; thus, it may be hypothesised that these cells contribute to altered EV pools in MS patient plasma. Interestingly, both leukocyte-derived EPs and $\mathrm{CD}^{+} \mathrm{T}$ cell-derived EPs were decreased in relapse patients compared to HCs and SPMS patients (Fig. 4).

The decrease of $\mathrm{CD} 4^{+} \mathrm{T}$-cell derived EPs in relapse patients may at first seem to contradict the theory that MS is largely driven by autoreactive $\mathrm{CD}^{+} \mathrm{T}$ cells (Dendrou et al., 2015). EV secretion increases in rapidly proliferating cells that are activated by the immune system (Selmaj et al., 2017) and under many pathological circumstances (Abels and Breakefield, 2016). So, an increase in $C D 4^{+} \mathrm{T}$ cell-derived EPs may be expected. However, a study by Jelcic et al. (Jelcic et al., 2018) indicated that while auto-proliferation of $\mathrm{CD}^{+} \mathrm{T}$ cells is elevated in MS patients during remission, it significantly decreases during relapse. This supports the finding of reduced circulating $\mathrm{CD}^{+} \mathrm{T}$ cell-derived EPs in relapse patients. These observations might reflect migration of pathogenic $\mathrm{CD}^{+}{ }^{+} \mathrm{T}$ cells into the CNS during relapse (Dendrou et al., 2015; Jelcic et al., 2018).

The decrease in $\mathrm{CD} 45^{+}$EPs in relapse patients may be similarly explained. CD45 is found on all differentiated haematopoietic cells with the exception of erythrocytes, platelets, and plasma cells (Hermiston et al., 2003). In this study, CD45 was exploited to enumerate EPs originating 
from all leukocytes. CD45 has been previously linked to MS, where a single nucleotide polymorphism (SNP), 77C $\rightarrow \mathrm{G}$, appeared to be overrepresented in MS patients. Individuals who carried this SNP had stronger expressions of the high molecular weight isoforms of CD45 (CD45RA, CD45RB, CD45RC), but decreased expression of full-length CD45 (CD45ABC) and CD45RO. Expression of high molecular weight isoforms of CD45 has been linked to prolonged immune cell activation, which may be contributing to the inflammation observed in MS patients leading up to a relapse (Jelcic et al., 2018; Vyshkina et al., 2004). The CD45 antibody used in this study (FITC, Clone 2D1, StemCell, Canada), can detect all CD45 isoforms. Thus, a decrease in $\mathrm{CD} 45^{+}$EPs in relapse patients may reflect the migration of activated inflammatory cells out of the blood compartment into the CNS during relapse. This hypothesis is also supported by the suggested increase in $\mathrm{CD} 45^{+}$EPs in MS patients following a relapse (Table 5). Concurrently, a suggestive negative correlation was observed between CD $45^{+}$EPs and time since relapse in SPMS patients (Table 5). This correlation may support the reduced peripheral involvement in later, more progressive stages of the disease (Dendrou et al., 2015).

One of the limitations of this study is that information regarding infectious diseases was not recorded at the time of sample collection. Hence, differences in $\mathrm{CD}_{4} 5^{+}$and $\mathrm{CD} 4^{+}$immune cellderived EPs may be driven by an inflammatory response to infection and not active relapse. Nonetheless, the significant decrease in $\mathrm{CD} 45^{+}$and $\mathrm{CD} 4^{+}$EPs in relapse patients only, supports that differences in these EP numbers are driven by MS-related disease activity in these patients rather than infection. Future studies should aim to record information on infectious diseases to further investigate this hypothesis.

Like $\mathrm{CD}^{+}$and $\mathrm{CD}^{+} 5^{+}$EPs, platelet-derived EPs also appeared to be decreased in relapse patients compared to both SPMS patients and HCs. In MS, activated platelets may bind to leukocytes and endothelial cells of the $\mathrm{BBB}$, as evidenced by ex vivo studies (Dziedzic and 
Bijak, 2019). P selectin on platelet-derived EVs has been observed to bind to its ligands Pselectin glycoprotein ligand 1 and platelet-endothelial cell adhesion molecule-1 on lymphocytes. This binding up-regulated the expression of $\alpha 4 \beta 1$ integrins, facilitating lymphocyte tethering to the BBB (Saenz-Cuesta et al., 2014b; Sheremata et al., 2008). A decrease in platelet-derived EPs during relapse may reflect the timing of sample collection. Relapse samples were collected after patients presented with new neurological symptoms or gadolinium-enhancing lesions on MRI, so arguably after lymphocytes gained access to the CNS through a damaged BBB (Dendrou et al., 2015; Jelcic et al., 2018). Thus, platelets and platelet-derived EPs involved in the breach of BBB integrity and lymphocyte infiltration may no longer be detectable in the circulation at this point. A possible increase in platelet-derived EPs was observed after relapse, as evidenced by the suggestive correlation between CD41 $\mathrm{b}^{+}$ EPs and time since relapse (Table 5). Previous studies reported an increase in CD61 $1^{+}$plateletderived EVs in RRMS patients during remission (Saenz-Cuesta et al., 2014a; Sheremata et al., 2008). While a similar trend can be observed in RRMS patients recruited for this study, it is not statistically significant and the use of different clusters of differentiation (CDs) and small sample size may account for these discrepancies. As seen in Table 1, the same CD molecule is expressed on more than one cell population and similarly more than one $\mathrm{CD}$ molecule may be characteristic of a given cell, making it difficult to sensitively and specifically characterise the cellular origin of EPs and EVs based on a single CD marker (Clark et al., 2016). Typically, cells are characterised based on the presence and absence of multiple CDs and failure to characterise the cellular origin of EPs using a multitude of CD markers is one of the limitations of this study.

Endothelium-derived EPs were increased in RRMS patients and are likely reflecting the activated and damaged endothelium, which enables lymphocytic infiltration (Dendrou et al., 2015). They also suggestively correlated with the total number of relapses RRMS patients 
suffered (Table 5), possibly reflecting increased chronic BBB damage in these patients. Other studies have also found endothelium-derived EVs to reflect chronic BBB damage (SaenzCuesta et al., 2014b).

Interestingly, erythrocyte-derived EPs were increased during relapse. Erythrocytes may be involved in MS by contributing to oxidative stress in the periphery and BBB damage through altered phenotypes (Groen et al., 2016). Erythrocyte-derived EVs are known to be inflammatory (Danesh et al., 2014) and may also be involved in BBB damage (Mantel et al., 2016), but have not yet been investigated in MS. In Parkinson's disease, erythrocyte-derived EVs were found to cross the BBB and carry $\alpha$-synuclein into the CNS, contributing to its pathogenic accumulation (Matsumoto et al., 2017b). In MS, erythrocyte-derived EVs may be involved in inflammation, BBB disruption, or communication between the blood compartment and the CNS, but further research is needed to investigate all three hypotheses.

Several of the EP subtypes correlated with each other (Table 4), possibly indicating coordinated activation of their cells of origin, especially during relapse. As EPs are typically released in response to cellular activation, proliferation, or pathology (Selmaj et al., 2017), further investigation of this coordinated EP release may provide additional insights into the crosstalk between different cells in MS. While correlations between EPs of different cells may raise questions around their distinction, this study only looked at one EP surface marker. EP cargo and functions may prove more variable. It is hypothesised that correlations between EPs merely indicate simultaneous activation or stress of their cells of origin and not necessarily that the EPs are the same. For instance, erythrocyte- and platelet-derived EPs may be contributing to BBB damage (Jy et al., 2004; Mantel et al., 2016), whereas an increase in endothelial-derived EPs may simply be a result of this damage (Saenz-Cuesta et al., 2014b). 
While moderate correlations were identified between CD14 \& CD20 positive EPs and CD146 \& CD235a positive EPs in all samples combined, these correlations were not identified in the subgroup analysis (Table 4). This may be a reflection of the small sample size as trends toward these correlations were identified in the subgroups, though these did not reach significance (data not shown).

Further, only around $10 \%$ of all EPs stained positive for the selected CD markers (Table 3). The remaining EPs may include protein aggregates, lipoproteins, and EPs from other cells of origin. However, as previously noted (Alberro et al., 2019), EPs only harbouring a few CD markers may not be counted as positive for a given CD molecule. It also appears that not every cell surface marker ends up on the cell's EPs. CD45 is expressed on all leukocytes with the exception of plasma cells (Vyshkina et al., 2004), yet CD45 ${ }^{+}$EPs were not always more numerous than $\mathrm{CD}^{+}, \mathrm{CD}^{+}$, and $\mathrm{CD} 20^{+}$EPs combined. Consequently, circulating EP numbers from investigated cells of origin may be greater than reported.

There were several suggestive correlations between circulating EPs and clinical measures; however, following correction for multiple comparisons, none of the correlations remained statistically significant. This may be due to the small sample size of this underpowered study, particularly when considering the correlation between B cell-derived EPs and progression duration in SPMS patients, which remained nearly statistically significant (adjusted p-value $=$ 0.055) (Table 5). B cells have been previously linked to progressive MS (Romme Christensen et al., 2013). Therefore, B cell-derived EPs may relate information from peripheral B cells to the CNS to contribute to the disease. Evidence of B cell-derived EPs in SPMS patients' CSF would support this hypothesis and should be assessed by future studies. EP numbers did not correlate with bench time, indicating that the prolonged bench time (4-6 h) of 11 samples (approx. 17\% of samples) did not affect the results of this study. 
While some studies have looked at EV surface markers as a potential source of biomarkers (Saenz-Cuesta et al., 2014b), this study has found EP surface markers to be non-specific. Age and body mass index (Table 5) may be affecting circulating EP levels, which has also been highlighted by other studies (Enjeti et al., 2017). This lack of specificity indicates that EP surface markers may not be suitable as biomarkers. Nonetheless, there may be merit in investigating the cargo of EVs for such purposes.

\section{Conclusions}

In conclusion, the numbers of several circulating EPs are altered during relapse, indicating altered intercellular communication in the peripheral blood compartment during disease activity. Differences in circulating EP levels are not all specific to disease or disease subtype and some alterations may be driven by other factors, such as age and body mass index. However, further research into circulating EPs (and EVs) in larger cohorts, so that adjustments for confounding factors can be made, and using an expanded panel of markers may provide clues into their role in MS pathogenesis. An improved understanding of EV communication in MS could lead to the discovery of targets for new therapies and an improved understanding of disease pathology, especially regarding the communication between the peripheral blood compartment and the CNS. 


\section{Figure Legends:}

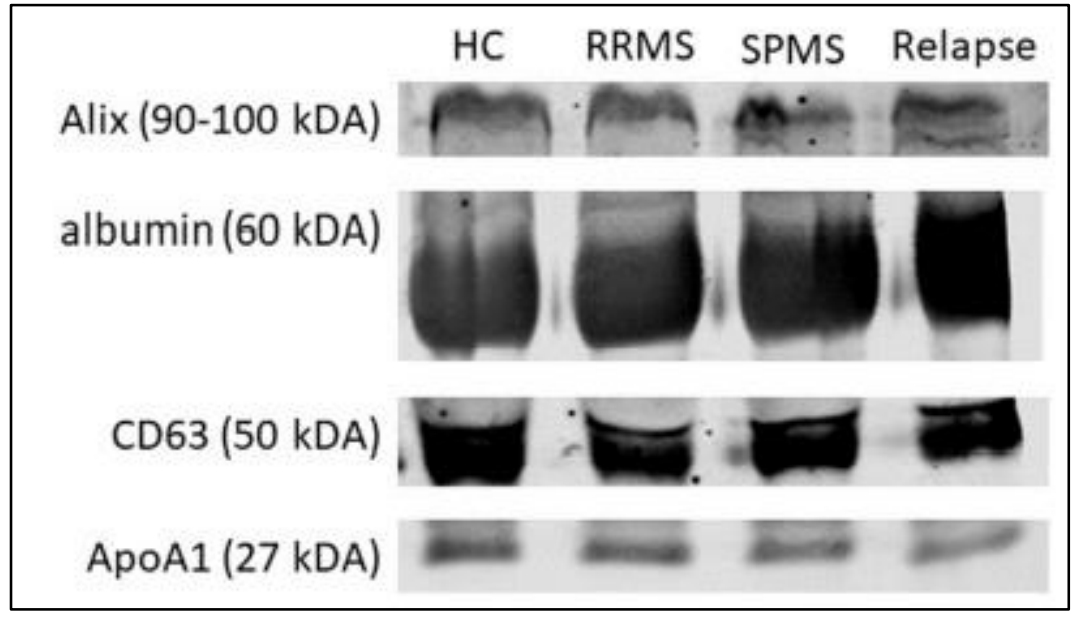

Figure 1: Sample characteristics. Sample western blots of platelet-free plasma looking at Alix, albumin, CD63 and ApoA1 in one sample of median EP number in each group (HC, RRMS, SPMS, Relapse). Full western blots are shown in Supplementary Figure S1. EP: extracellular particle; HC - healthy control; RRMS - relapsing-remitting Multiple Sclerosis; SPMS - secondary progressive Multiple Sclerosis.

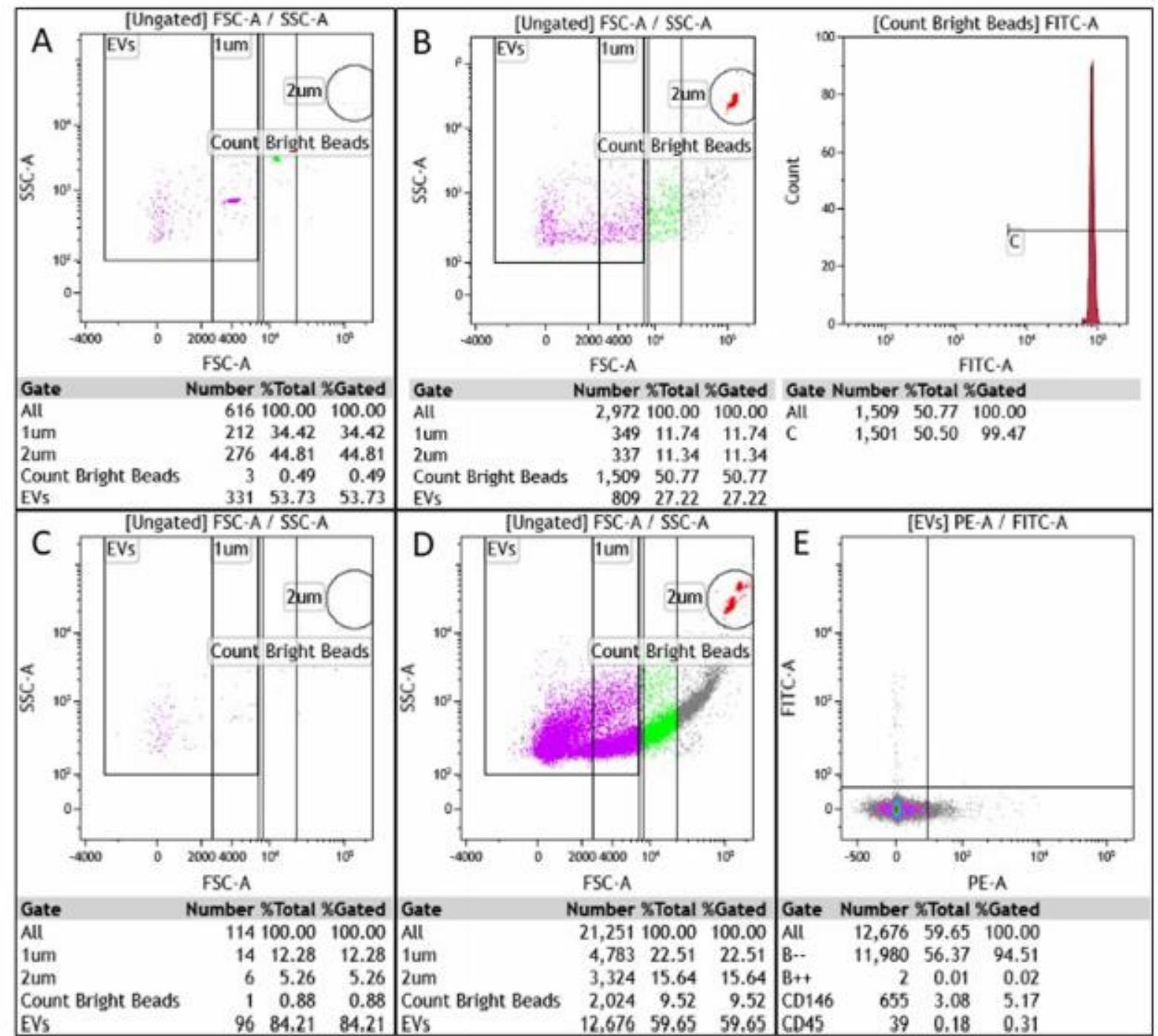


Figure 2: Gating strategies for extracellular particle flow cytometry. A: Size reference beads $(1 \mu \mathrm{m}$ and $2 \mu \mathrm{m})$ run for 30 seconds on high flow rate. B: CountBright beads (red in circle) run for $30 \mathrm{sec}$ on high flow rate. Only CountBright beads that fell into the circular gate on the forward-scatter/side-scatter plot and stained positive for FITC (C gate) were counted. C: Filtered staining buffer run for $30 \mathrm{sec}$ on high flow rate. D: Platelet-free plasma sample run on low flow rate until 1500 CountBright beads were obtained. E: The same platelet-free plasma as panel D, gated for CD146 (PE) and CD45 (FITC) positive events.

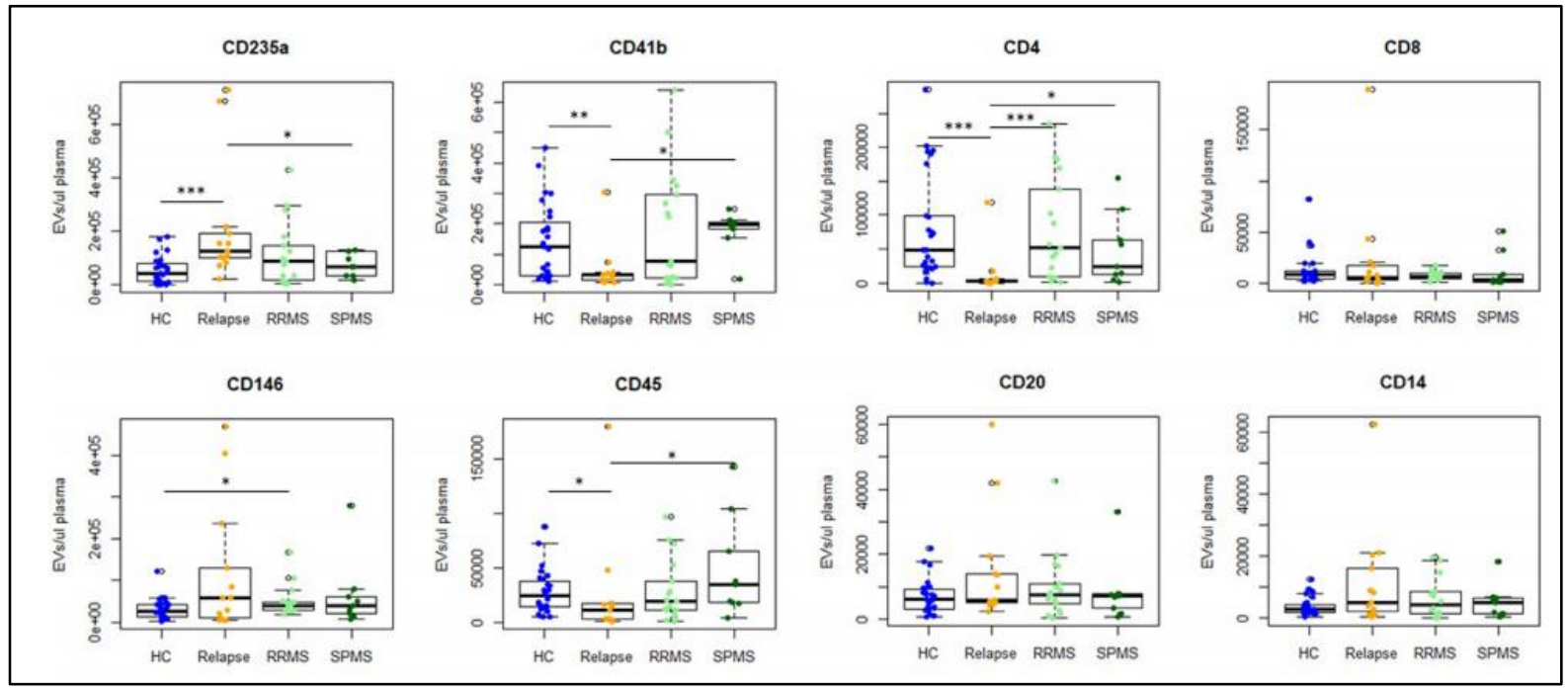

Figure 3: Tukey boxplots of plasma-borne extracellular particles. Concentrations of plasma-borne erythrocyte- (CD235a), platelet- (CD41b), endothelium- (CD146), leukocyte(CD45), as well as $\mathrm{CD}^{+}{ }^{+} \mathrm{T}$ cell- $(\mathrm{CD} 4), \mathrm{CD}^{+} \mathrm{T}$ cell- $(\mathrm{CD} 8)$, B cell- (CD20), and monocytederived (CD14) EPs are shown by subject group (HC: $n=27$, blue; Relapse: $n=13$, orange; RRMS (stable): $\mathrm{n}=17$, light green; SPMS: $\mathrm{n}=9$, dark green). White circles represent outliers defined as deviating more than 1.5-fold from the upper/lower quartile. EP - extracellular particle; HC - healthy control; RRMS - relapsing-remitting Multiple Sclerosis; SPMS secondary progressive Multiple Sclerosis; *** - $\mathrm{p}<0.001$; ** $-\mathrm{p}<0.01$; * $-\mathrm{p}<0.05$.

\section{Supplementary Material:}

Supplementary File S1: Additional participant and sample information. 


\section{Acknowledgements:}

We would like to acknowledge Dr Anoop Enjeti and Ms Nicole Cole for their assistance with flow cytometry experiments. Further, we would like to extend our gratitude towards Dr Mohammad Amin, Dr Neha Nandal, and Dr Myintzu Min for their help with patient recruitment, to Mr Sean Burnard for his assistance with blood processing, and to all the MS patients and healthy volunteers who donated their blood and time to this study.

\section{Author contributions:}

Kira Groen: Conceptualisation, Funding acquisition, Methodology, Investigation, Data curation, Formal analysis, Visualisation, Writing - original draft \& reviewing and editing, Project administration

Vicki E. Maltby: Conceptualisation, Funding acquisition, Methodology, Writing - reviewing and editing, Project administration, Supervision

Rodney J. Scott: Conceptualisation, Funding acquisition, Methodology, Writing - reviewing and editing, Supervision

Lotti Tajouri: Conceptualisation, Writing - reviewing and editing, Supervision

Jeannette Lechner-Scott: Conceptualisation, Funding acquisition, Writing - reviewing and editing, Project administration, Supervision

\section{Funding:}

This study was funded by a MS Research Australia Incubator Grant (18-0383) and Research Student Support funds from the University of Newcastle. K. Groen is funded by a scholarship from the University of Newcastle. V.E. Maltby is funded by fellowships from MS Research Australia and the Canadian Institutes of Health Research. The above mentioned funding sources had no involvement in study design; in collection, analysis, or interpretation of data; in the writing of the manuscript; or in the decision to submit the article for publication.

\section{Conflicts of interest:}

Professor J. Lechner-Scott's institution receives non-directed funding, as well as honoraria for presentations and membership on advisory boards from Sanofi Genzyme, Biogen, Merck, Teva, Roche, and Novartis Australia. V.E. Maltby has received honoraria for presentations from Merck and Biogen. 


\section{References:}

Abels, E.R., Breakefield, X.O., 2016. Introduction to Extracellular Vesicles: Biogenesis, RNA Cargo Selection, Content, Release, and Uptake. Cellular and molecular neurobiology 36(3), 301-312.

Alberro, A., Osorio-Querejeta, I., Sepulveda, L., Fernandez-Eulate, G., Mateo-Abad, M., Munoz-Culla, M., Carregal-Romero, S., Matheu, A., Vergara, I., Lopez de Munain, A., Saenz-Cuesta, M., Otaegui, D., 2019. T cells and immune functions of plasma extracellular vesicles are differentially modulated from adults to centenarians. Aging 11(22), 1072310741.

An, K., Klyubin, I., Kim, Y., Jung, J.H., Mably, A.J., O'Dowd, S.T., Lynch, T., Kanmert, D., Lemere, C.A., Finan, G.M., Park, J.W., Kim, T.W., Walsh, D.M., Rowan, M.J., Kim, J.H., 2013. Exosomes neutralize synaptic-plasticity-disrupting activity of Abeta assemblies in vivo. Molecular brain 6, 47.

Butzkueven, H., Chapman, J., Cristiano, E., Grand'Maison, F., Hoffmann, M., Izquierdo, G., Jolley, D., Kappos, L., Leist, T., Pöhlau, D., Rivera, V., Trojano, M., Verheul, F., Malkowski, J.P., 2006. MSBase: an international, online registry and platform for collaborative outcomes research in multiple sclerosis. Multiple Sclerosis Journal 12(6), 769-774.

Clark, G., Stockinger, H., Balderas, R., van Zelm, M.C., Zola, H., Hart, D., Engel, P., 2016. Nomenclature of CD molecules from the Tenth Human Leucocyte Differentiation Antigen Workshop. Clinical \& translational immunology 5(1), e57-e57.

Danesh, A., Inglis, H.C., Jackman, R.P., Wu, S., Deng, X., Muench, M.O., Heitman, J.W., Norris, P.J., 2014. Exosomes from red blood cell units bind to monocytes and induce proinflammatory cytokines, boosting T-cell responses in vitro. Blood 123(5), 687-696. Dendrou, C.A., Fugger, L., Friese, M.A., 2015. Immunopathology of multiple sclerosis. Nature Reviews Immunology 15(9), 545-558.

Dickens, A.M., Tovar, Y.R.L.B., Yoo, S.W., Trout, A.L., Bae, M., Kanmogne, M., Megra, B., Williams, D.W., Witwer, K.W., Gacias, M., Tabatadze, N., Cole, R.N., Casaccia, P., Berman, J.W., Anthony, D.C., Haughey, N.J., 2017. Astrocyte-shed extracellular vesicles regulate the peripheral leukocyte response to inflammatory brain lesions. Science signaling 10(473), eaai7696.

Dziedzic, A., Bijak, M., 2019. Interactions between platelets and leukocytes in pathogenesis of multiple sclerosis. Advances in clinical and experimental medicine : official organ Wroclaw Medical University 28(2), 277-285.

Enjeti, A.K., Ariyarajah, A., D'Crus, A., Seldon, M., Lincz, L.F., 2016. Correlative analysis of nanoparticle tracking, flow cytometric and functional measurements for circulating microvesicles in normal subjects. Thrombosis Research 145, 18-23.

Enjeti, A.K., Ariyarajah, A., D'Crus, A., Seldon, M., Lincz, L.F., 2017. Circulating microvesicle number, function and small RNA content vary with age, gender, smoking status, lipid and hormone profiles. Thrombosis Research 156, 65-72.

García-Romero, N., Carrión-Navarro, J., Esteban-Rubio, S., Lázaro-Ibáñez, E., Peris-Celda, M., Alonso, M.M., Guzmán-De-Villoria, J., Fernández-Carballal, C., de Mendivil, A.O., García-Duque, S., Escobedo-Lucea, C., Prat-Acín, R., Belda-Iniesta, C., Ayuso-Sacido, A., 2017. DNA sequences within glioma-derived extracellular vesicles can cross the intact bloodbrain barrier and be detected in peripheral blood of patients. Oncotarget 8(1), 1416-1428.

Groen, K., Maltby, V.E., Sanders, K.A., Scott, R.J., Tajouri, L., Lechner-Scott, J., 2016. Erythrocytes in multiple sclerosis-forgotten contributors to the pathophysiology? Multiple Sclerosis Journal-Experimental, Translational and Clinical 2, 2055217316649981.

Hermiston, M.L., Xu, Z., Weiss, A., 2003. CD45: a critical regulator of signaling thresholds in immune cells. Annual review of immunology 21, 107-137. 
Iwai, K., Yamamoto, S., Yoshida, M., Shiba, K., 2017. Isolation of Extracellular Vesicles in Saliva Using Density Gradient Ultracentrifugation. Methods in molecular biology (Clifton, N.J.) 1660, 343-350.

Jelcic, I., Al Nimer, F., Wang, J., Lentsch, V., Planas, R., Jelcic, I., Madjovski, A., Ruhrmann, S., Faigle, W., Frauenknecht, K., Pinilla, C., Santos, R., Hammer, C., Ortiz, Y., Opitz, L., Gronlund, H., Rogler, G., Boyman, O., Reynolds, R., Lutterotti, A., Khademi, M., Olsson, T., Piehl, F., Sospedra, M., Martin, R., 2018. Memory B Cells Activate BrainHoming, Autoreactive CD4(+) T Cells in Multiple Sclerosis. Cell 175(1), 85-100.e123. Jy, W., Minagar, A., Jimenez, J.J., Sheremata, W.A., Mauro, L.M., Horstman, L.L., Bidot, C., Ahn, Y.S., 2004. Endothelial microparticles (EMP) bind and activate monocytes: elevated EMP-monocyte conjugates in multiple sclerosis. Frontiers in bioscience : a journal and virtual library 9, 3137-3144.

Lublin, F.D., Reingold, S.C., Cohen, J.A., Cutter, G.R., Sorensen, P.S., Thompson, A.J., Wolinsky, J.S., Balcer, L.J., Banwell, B., Barkhof, F., Bebo, B., Jr., Calabresi, P.A., Clanet, M., Comi, G., Fox, R.J., Freedman, M.S., Goodman, A.D., Inglese, M., Kappos, L., Kieseier, B.C., Lincoln, J.A., Lubetzki, C., Miller, A.E., Montalban, X., O'Connor, P.W., Petkau, J., Pozzilli, C., Rudick, R.A., Sormani, M.P., Stuve, O., Waubant, E., Polman, C.H., 2014. Defining the clinical course of multiple sclerosis: the 2013 revisions. Neurology 83(3), 278286.

Mantel, P.Y., Hjelmqvist, D., Walch, M., Kharoubi-Hess, S., Nilsson, S., Ravel, D., Ribeiro, M., Gruring, C., Ma, S., Padmanabhan, P., Trachtenberg, A., Ankarklev, J., Brancucci, N.M., Huttenhower, C., Duraisingh, M.T., Ghiran, I., Kuo, W.P., Filgueira, L., Martinelli, R., Marti, M., 2016. Infected erythrocyte-derived extracellular vesicles alter vascular function via regulatory Ago2-miRNA complexes in malaria. Nature communications 7, 12727.

Marcos-Ramiro, B., Oliva Nacarino, P., Serrano-Pertierra, E., Blanco-Gelaz, M.A., Weksler, B.B., Romero, I.A., Couraud, P.O., Tunon, A., Lopez-Larrea, C., Millan, J., CernudaMorollon, E., 2014. Microparticles in multiple sclerosis and clinically isolated syndrome: effect on endothelial barrier function. BMC neuroscience 15, 110.

Matsumoto, J., Stewart, T., Banks, W.A., Zhang, J., 2017a. The transport mechanism of extracellular vesicles at the blood-brain barrier. Current Pharmaceutical Design 23(40), 62066214.

Matsumoto, J., Stewart, T., Sheng, L., Li, N., Bullock, K., Song, N., Shi, M., Banks, W.A., Zhang, J., 2017b. Transmission of alpha-synuclein-containing erythrocyte-derived extracellular vesicles across the blood-brain barrier via adsorptive mediated transcytosis: another mechanism for initiation and progression of Parkinson's disease? Acta neuropathologica communications 5(1), 71.

Minagar, A., Jy, W., Jimenez, J.J., Sheremata, W.A., Mauro, L.M., Mao, W.W., Horstman, L.L., Ahn, Y.S., 2001. Elevated plasma endothelial microparticles in multiple sclerosis. Neurology 56(10), 1319-1324.

Norton, K., Norton, L., Sadgrove, D., 2010. Position statement on physical activity and exercise intensity terminology. Journal of science and medicine in sport 13(5), 496-502. Pisitkun, T., Shen, R.F., Knepper, M.A., 2004. Identification and proteomic profiling of exosomes in human urine. Proc Natl Acad Sci USA 101(36), 13368-13373.

Ridder, K., Keller, S., Dams, M., Rupp, A.K., Schlaudraff, J., Del Turco, D., Starmann, J., Macas, J., Karpova, D., Devraj, K., Depboylu, C., Landfried, B., Arnold, B., Plate, K.H., Hoglinger, G., Sultmann, H., Altevogt, P., Momma, S., 2014. Extracellular vesicle-mediated transfer of genetic information between the hematopoietic system and the brain in response to inflammation. PloS one 12(6), e1001874.

Romme Christensen, J., Bornsen, L., Ratzer, R., Piehl, F., Khademi, M., Olsson, T., Sorensen, P.S., Sellebjerg, F., 2013. Systemic inflammation in progressive multiple sclerosis 
involves follicular T-helper, Th17- and activated B-cells and correlates with progression. PloS one 8(3), e57820.

Saenz-Cuesta, M., Irizar, H., Castillo-Trivino, T., Munoz-Culla, M., Osorio-Querejeta, I., Prada, A., Sepulveda, L., Lopez-Mato, M.P., Lopez de Munain, A., Comabella, M., Villar, L.M., Olascoaga, J., Otaegui, D., 2014a. Circulating microparticles reflect treatment effects and clinical status in multiple sclerosis. Biomarkers in medicine 8(5), 653-661.

Saenz-Cuesta, M., Osorio-Querejeta, I., Otaegui, D., 2014b. Extracellular Vesicles in Multiple Sclerosis: What are They Telling Us? Frontiers in Cellular Neuroscience 8, 100. Selmaj, I., Mycko, M.P., Raine, C.S., Selmaj, K.W., 2017. The role of exosomes in CNS inflammation and their involvement in multiple sclerosis. Journal of neuroimmunology 306, $1-10$.

Sheremata, W.A., Jy, W., Delgado, S., Minagar, A., McLarty, J., Ahn, Y., 2006. Interferonbeta1a reduces plasma CD31+ endothelial microparticles (CD31+EMP) in multiple sclerosis. J Neuroinflammation 3, 23.

Sheremata, W.A., Jy, W., Horstman, L.L., Ahn, Y.S., Alexander, J.S., Minagar, A., 2008. Evidence of platelet activation in multiple sclerosis. J Neuroinflammation 5, 27.

Thery, C., Witwer, K.W., Aikawa, E., Alcaraz, M.J., Anderson, J.D., Andriantsitohaina, R., Antoniou, A., Arab, T., Archer, F., Atkin-Smith, G.K., Ayre, D.C., Bach, J.M., Bachurski, D., Baharvand, H., Balaj, L., Baldacchino, S., Bauer, N.N., Baxter, A.A., Bebawy, M., Beckham, C., Bedina Zavec, A., Benmoussa, A., Berardi, A.C., Bergese, P., Bielska, E., Blenkiron, C., Bobis-Wozowicz, S., Boilard, E., Boireau, W., Bongiovanni, A., Borras, F.E., Bosch, S., Boulanger, C.M., Breakefield, X., Breglio, A.M., Brennan, M.A., Brigstock, D.R., Brisson, A., Broekman, M.L., Bromberg, J.F., Bryl-Gorecka, P., Buch, S., Buck, A.H., Burger, D., Busatto, S., Buschmann, D., Bussolati, B., Buzas, E.I., Byrd, J.B., Camussi, G., Carter, D.R., Caruso, S., Chamley, L.W., Chang, Y.T., Chen, C., Chen, S., Cheng, L., Chin, A.R., Clayton, A., Clerici, S.P., Cocks, A., Cocucci, E., Coffey, R.J., Cordeiro-da-Silva, A., Couch, Y., Coumans, F.A., Coyle, B., Crescitelli, R., Criado, M.F., D'Souza-Schorey, C., Das, S., Datta Chaudhuri, A., de Candia, P., De Santana, E.F., De Wever, O., Del Portillo, H.A., Demaret, T., Deville, S., Devitt, A., Dhondt, B., Di Vizio, D., Dieterich, L.C., Dolo, V., Dominguez Rubio, A.P., Dominici, M., Dourado, M.R., Driedonks, T.A., Duarte, F.V., Duncan, H.M., Eichenberger, R.M., Ekstrom, K., El Andaloussi, S., Elie-Caille, C., Erdbrugger, U., Falcon-Perez, J.M., Fatima, F., Fish, J.E., Flores-Bellver, M., Forsonits, A., Frelet-Barrand, A., Fricke, F., Fuhrmann, G., Gabrielsson, S., Gamez-Valero, A., Gardiner, C., Gartner, K., Gaudin, R., Gho, Y.S., Giebel, B., Gilbert, C., Gimona, M., Giusti, I., Goberdhan, D.C., Gorgens, A., Gorski, S.M., Greening, D.W., Gross, J.C., Gualerzi, A., Gupta, G.N., Gustafson, D., Handberg, A., Haraszti, R.A., Harrison, P., Hegyesi, H., Hendrix, A., Hill, A.F., Hochberg, F.H., Hoffmann, K.F., Holder, B., Holthofer, H., Hosseinkhani, B., Hu, G., Huang, Y., Huber, V., Hunt, S., Ibrahim, A.G., Ikezu, T., Inal, J.M., Isin, M., Ivanova, A., Jackson, H.K., Jacobsen, S., Jay, S.M., Jayachandran, M., Jenster, G., Jiang, L., Johnson, S.M., Jones, J.C., Jong, A., Jovanovic-Talisman, T., Jung, S., Kalluri, R., Kano, S.I., Kaur, S., Kawamura, Y., Keller, E.T., Khamari, D., Khomyakova, E., Khvorova, A., Kierulf, P., Kim, K.P., Kislinger, T., Klingeborn, M., Klinke, D.J., 2nd, Kornek, M., Kosanovic, M.M., Kovacs, A.F., Kramer-Albers, E.M., Krasemann, S., Krause, M., Kurochkin, I.V., Kusuma, G.D., Kuypers, S., Laitinen, S., Langevin, S.M., Languino, L.R., Lannigan, J., Lasser, C., Laurent, L.C., Lavieu, G., Lazaro-Ibanez, E., Le Lay, S., Lee, M.S., Lee, Y.X.F., Lemos, D.S., Lenassi, M., Leszczynska, A., Li, I.T., Liao, K., Libregts, S.F., Ligeti, E., Lim, R., Lim, S.K., Line, A., Linnemannstons, K., Llorente, A., Lombard, C.A., Lorenowicz, M.J., Lorincz, A.M., Lotvall, J., Lovett, J., Lowry, M.C., Loyer, X., Lu, Q., Lukomska, B., Lunavat, T.R., Maas, S.L., Malhi, H., Marcilla, A., Mariani, J., Mariscal, J., Martens-Uzunova, E.S., Martin-Jaular, L., Martinez, M.C., Martins, V.R., Mathieu, M., 
Mathivanan, S., Maugeri, M., McGinnis, L.K., McVey, M.J., Meckes, D.G., Jr., Meehan, K.L., Mertens, I., Minciacchi, V.R., Moller, A., Moller Jorgensen, M., Morales-Kastresana, A., Morhayim, J., Mullier, F., Muraca, M., Musante, L., Mussack, V., Muth, D.C., Myburgh, K.H., Najrana, T., Nawaz, M., Nazarenko, I., Nejsum, P., Neri, C., Neri, T., Nieuwland, R., Nimrichter, L., Nolan, J.P., Nolte-'t Hoen, E.N., Noren Hooten, N., O'Driscoll, L., O'Grady, T., O'Loghlen, A., Ochiya, T., Olivier, M., Ortiz, A., Ortiz, L.A., Osteikoetxea, X., Ostergaard, O., Ostrowski, M., Park, J., Pegtel, D.M., Peinado, H., Perut, F., Pfaffl, M.W., Phinney, D.G., Pieters, B.C., Pink, R.C., Pisetsky, D.S., Pogge von Strandmann, E., Polakovicova, I., Poon, I.K., Powell, B.H., Prada, I., Pulliam, L., Quesenberry, P., Radeghieri, A., Raffai, R.L., Raimondo, S., Rak, J., Ramirez, M.I., Raposo, G., Rayyan, M.S., Regev-Rudzki, N., Ricklefs, F.L., Robbins, P.D., Roberts, D.D., Rodrigues, S.C., Rohde, E., Rome, S., Rouschop, K.M., Rughetti, A., Russell, A.E., Saa, P., Sahoo, S., SalasHuenuleo, E., Sanchez, C., Saugstad, J.A., Saul, M.J., Schiffelers, R.M., Schneider, R., Schoyen, T.H., Scott, A., Shahaj, E., Sharma, S., Shatnyeva, O., Shekari, F., Shelke, G.V., Shetty, A.K., Shiba, K., Siljander, P.R., Silva, A.M., Skowronek, A., Snyder, O.L., 2nd, Soares, R.P., Sodar, B.W., Soekmadji, C., Sotillo, J., Stahl, P.D., Stoorvogel, W., Stott, S.L., Strasser, E.F., Swift, S., Tahara, H., Tewari, M., Timms, K., Tiwari, S., Tixeira, R., Tkach, M., Toh, W.S., Tomasini, R., Torrecilhas, A.C., Tosar, J.P., Toxavidis, V., Urbanelli, L., Vader, P., van Balkom, B.W., van der Grein, S.G., Van Deun, J., van Herwijnen, M.J., Van Keuren-Jensen, K., van Niel, G., van Royen, M.E., van Wijnen, A.J., Vasconcelos, M.H., Vechetti, I.J., Jr., Veit, T.D., Vella, L.J., Velot, E., Verweij, F.J., Vestad, B., Vinas, J.L., Visnovitz, T., Vukman, K.V., Wahlgren, J., Watson, D.C., Wauben, M.H., Weaver, A., Webber, J.P., Weber, V., Wehman, A.M., Weiss, D.J., Welsh, J.A., Wendt, S., Wheelock, A.M., Wiener, Z., Witte, L., Wolfram, J., Xagorari, A., Xander, P., Xu, J., Yan, X., YanezMo, M., Yin, H., Yuana, Y., Zappulli, V., Zarubova, J., Zekas, V., Zhang, J.Y., Zhao, Z., Zheng, L., Zheutlin, A.R., Zickler, A.M., Zimmermann, P., Zivkovic, A.M., Zocco, D., ZubaSurma, E.K., 2018. Minimal information for studies of extracellular vesicles 2018 (MISEV2018): a position statement of the International Society for Extracellular Vesicles and update of the MISEV2014 guidelines. Journal of extracellular vesicles 7(1), 1535750. Thompson, A.J., Banwell, B.L., Barkhof, F., Carroll, W.M., Coetzee, T., Comi, G., Correale, J., Fazekas, F., Filippi, M., Freedman, M.S., Fujihara, K., Galetta, S.L., Hartung, H.P., Kappos, L., Lublin, F.D., Marrie, R.A., Miller, A.E., Miller, D.H., Montalban, X., Mowry, E.M., Sorensen, P.S., Tintore, M., Traboulsee, A.L., Trojano, M., Uitdehaag, B.M.J., Vukusic, S., Waubant, E., Weinshenker, B.G., Reingold, S.C., Cohen, J.A., 2018. Diagnosis of multiple sclerosis: 2017 revisions of the McDonald criteria. The Lancet. Neurology 17(2), 162-173.

Vyshkina, T., Leist, T.P., Shugart, Y.Y., Kalman, B., 2004. CD45 (PTPRC) as a candidate gene in multiple sclerosis. Multiple sclerosis (Houndmills, Basingstoke, England) 10(6), 614617.

Zaborowski, M.P., Balaj, L., Breakefield, X.O., Lai, C.P., 2015. Extracellular Vesicles: Composition, Biological Relevance, and Methods of Study. Bioscience 65(8), 783-797. Zinger, A., Latham, S.L., Combes, V., Byrne, S., Barnett, M.H., Hawke, S., Grau, G.E., 2016. Plasma levels of endothelial and B-cell-derived microparticles are restored by fingolimod treatment in multiple sclerosis patients. Multiple sclerosis (Houndmills, Basingstoke, England) 22(14), 1883-1887. 
Supplementary File S1: Additional participant and sample information.

Supplementary Table S1: Additional participant and sample information.

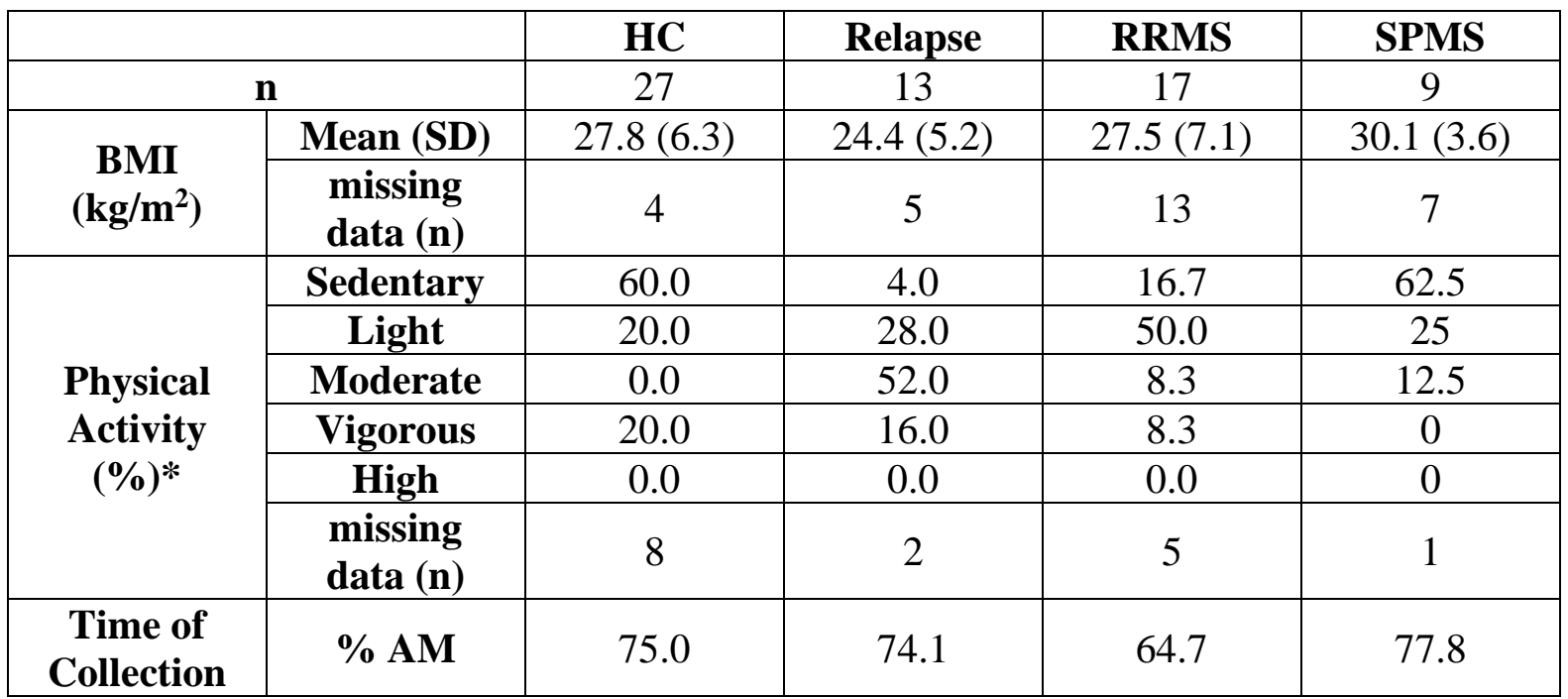

* Physical activity levels are based on the Exercise and Sport Science Australia intensity guidelines. BMI - body mass index; HC - healthy control; RRMS - relapsing-remitting Multiple Sclerosis; SD - standard deviation of the mean SPMS - secondary progressive Multiple Sclerosis.

Information on menopause, time of last exercise, diet, infectious and non-infectious other than MS diseases, and non-MS-related medications was not recorded as part of this study. Data for pregnancies and breastfeeding is not shown as participants who were pregnant or breastfeeding were excluded from this study.

Supplementary Table S2: Total particle:protein ratios.

\begin{tabular}{|l|c|c|c|}
\hline Sample & EPs/ $\mathbf{\mu l}$ & protein $(\boldsymbol{\mu g} / \mathbf{u l})$ & EP:protein \\
\hline HC 1 (min) & 638,009 & 93.6 & 6,816 \\
\hline HC 2 (median) & $3,111,339$ & 83.2 & 37,396 \\
\hline HC 3 (max) & $16,976,719$ & 98.4 & 172,528 \\
\hline Relapse 1 (min) & 914,385 & 72.4 & 12,630 \\
\hline Relapse 2 (median) & $2,430,248$ & 69.2 & 35,119 \\
\hline Relapse 3 (max) & $5,389,701$ & 90.4 & 59,621 \\
\hline RRMS 1 (min) & 752,476 & 89.2 & 8,436 \\
\hline RRMS 2 (median) & $2,363,787$ & 88.8 & 26,619 \\
\hline RRMS 3 (max) & $17,287,044$ & 80.8 & 213,949 \\
\hline SPMS 1 (min) & 818,247 & 78.0 & 10,490 \\
\hline SPMS 2 (median) & $2,415,863$ & 78.8 & 30,658 \\
\hline SPMS 3 (max) & $181,494,963$ & 97.6 & $1,859,580$ \\
\hline
\end{tabular}

Protein concentrations were measured for the sample with minimum, median and maximum total extracellular particle number in each group. EP - extracellular particle; HC - healthy control; RRMS - relapsing-remitting Multiple Sclerosis; SPMS - secondary progressive Multiple Sclerosis. 
Supplementary Figure S1: Full western blots.

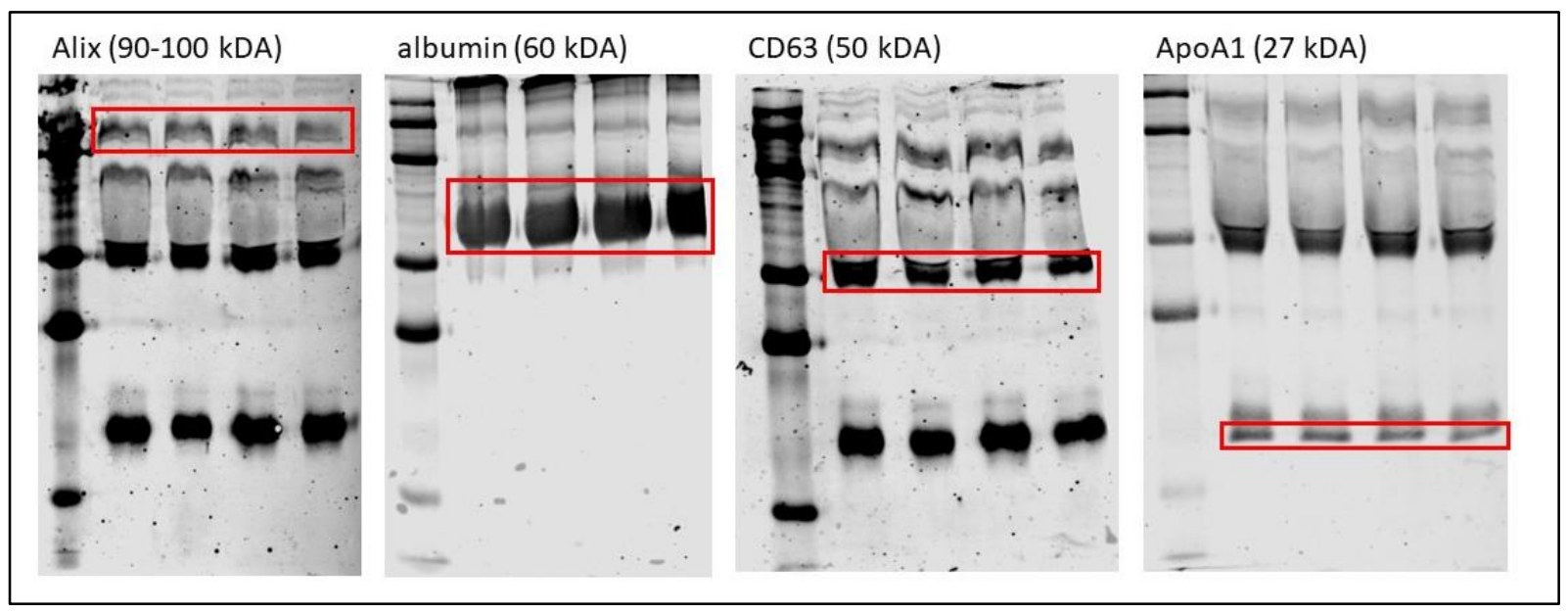

Supplementary Table S3: Correlations between extracellular particles and bench time.

\begin{tabular}{|l|c|c|}
\hline EP & Spearman's rho & p-value \\
\hline CD235a $^{+}$ & 0.381 & 0.338 \\
\hline CD41b $^{+}$ & 0.075 & 0.057 \\
\hline CD146 $^{+}$ & 0.187 & 0.855 \\
\hline CD45 $^{+}$ & 0.080 & 0.100 \\
\hline CD4 $^{+}$ & -0.165 & 0.972 \\
\hline CD20 $^{+}$ & 0.162 & 0.505 \\
\hline CD8 $^{+}$ & -0.009 & 0.036 \\
\hline CD14+ $^{+}$ & 0.000 & 0.228 \\
\hline
\end{tabular}

Correlation for all samples $(n=66)$. EP - extracellular particle. 
Supplementary Figure S2: Percent stained extracellular particles. Pie charts of the total EPs (200-1000 nm) detected by flow cytometry and the proportions that stained positive for selected CD markers. Values represent median particle number for each CD marker. Data from all four groups (HC, RRMS, SPMS, and Relapse, $n=66$ ) was combined. CD - cluster of differentiation; EP - extracellular particle; HC - healthy control; RRMS - relapsing-remitting Multiple Sclerosis; SPMS - secondary progressive Multiple Sclerosis.

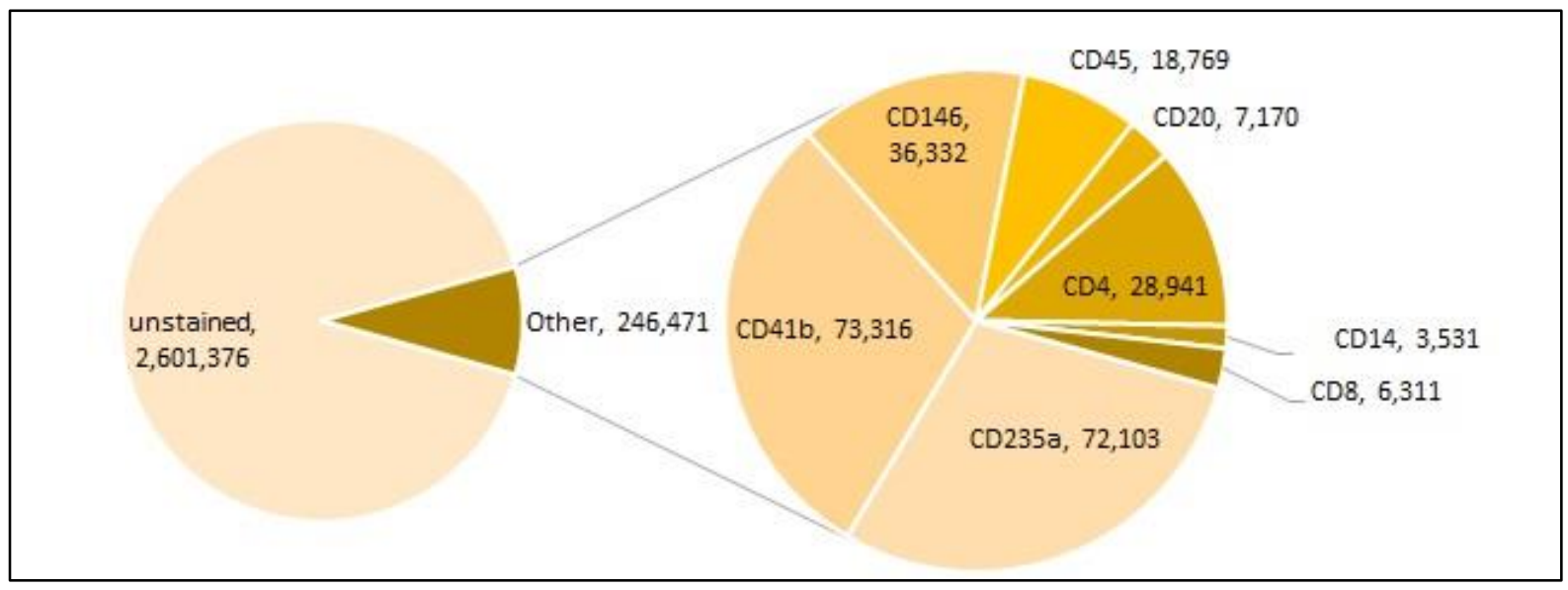


Supplementary Table S4: Number of circulating plasma extracellular particles by cell of origin and subject group.

\begin{tabular}{|c|c|c|c|c|c|c|c|c|}
\hline & \multicolumn{2}{|c|}{ HC } & \multicolumn{2}{|c|}{ Relapse } & \multicolumn{2}{|c|}{ RRMS } & \multicolumn{2}{|c|}{ SPMS } \\
\hline $\mathbf{n}$ & \multicolumn{2}{|c|}{27} & \multicolumn{2}{|c|}{13} & \multicolumn{2}{|c|}{17} & \multicolumn{2}{|c|}{9} \\
\hline & median & IQR & median & IQR & median & IQR & median & IQR \\
\hline $\begin{array}{l}\text { CD235a positive } \\
\text { EPs/ul plasma }\end{array}$ & 40,125 & 68,040 & 126,112 & 93,955 & 88,674 & 125,983 & 67,343 & 89,976 \\
\hline $\begin{array}{l}\text { CD41b positive } \\
\text { EPs/ul plasma }\end{array}$ & 123,854 & 175,369 & 31,387 & 20,732 & 75,173 & 274,905 & 196,814 & 22,210 \\
\hline $\begin{array}{l}\text { CD146 positive } \\
\text { EPs/ } \mu \text { l plasma }\end{array}$ & 26,400 & 28,211 & 56,923 & 119,046 & 40,267 & 19,977 & 38,627 & 41,088 \\
\hline $\begin{array}{l}\text { CD45 positive } \\
\text { EPs/ } \mu \text { l plasma }\end{array}$ & 24,704 & 23,363 & 11,378 & 14,495 & 19,229 & 26,946 & 35,107 & 46,784 \\
\hline 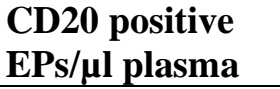 & 6,261 & 6,066 & 5,836 & 8,742 & 7,750 & 6,090 & 7,205 & 4,301 \\
\hline $\begin{array}{l}\text { CD4 positive } \\
\text { EPs/ } \mu \text { l plasma }\end{array}$ & 47,716 & 74,719 & 2,282 & 4,353 & 51,768 & 129,340 & 24,005 & 51,826 \\
\hline $\begin{array}{l}\text { CD8 positive } \\
\text { EPs/ } \mu \text { l plasma }\end{array}$ & 8,307 & 7,504 & 5,098 & 14,080 & 6,127 & 4,945 & 3,023 & 6,857 \\
\hline $\begin{array}{l}\text { CD14 positive } \\
\text { EPs/ul plasma }\end{array}$ & 2,965 & 2,521 & 4,936 & 13,861 & 4,422 & 6,949 & 5,061 & 4,872 \\
\hline
\end{tabular}

$\mathrm{EP}$ - extracellular particle; HC - healthy control; IQR - interquartile range; RRMS - relapsingremitting Multiple Sclerosis; SPMS - secondary progressive Multiple Sclerosis. 